\title{
Graphic Organizers as a Reading Strategy: Research Findings and Issues
}

\author{
Polyxeni Manoli, Maria Papadopoulou \\ Department of Early Childhood Education, University of Thessaly, Volos, Greece \\ Email: pegyma@hotmail.com, mariapap@uth.gr

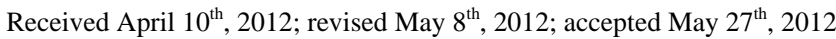

\begin{abstract}
The present article extends prior research on graphic organizers mainly used as a reading strategy. Graphic strategies, visual representation of information in a text, refer to different approaches to reading from the traditional, linear text representation. This study constitutes an attempt to shed light on the research evidence regarding the effectiveness of GOs on text learning and the various types of graphic organizers, which use different conventions to communicate information and are classified in various ways. As such, it highlights key concepts, the theoretical and historical foundations of graphic organizers, includes the major types of graphic organizers, summarizes research findings, recommends ways of integrating them in reading lessons, touches on the issue of strategy instruction and its effects on language learning and leaves room for further exploration.
\end{abstract}

Keywords: Graphic Organizers; Reading Comprehension; Reading Strategies

\section{Introduction}

The present article focuses on Graphic Organizers (GOs) as a reading strategy used both in the teaching and learning of languages and in content areas, like science, social studies. When GOs are used in the various content areas, the main goal is to boost comprehension skills in the target subject area, whereas, when they are deployed in the various language courses, the main aims are to improve students' reading comprehension skills and contribute to the acquisition of the target language. An attempt was made to include a number of studies that are representative of research on GOs. A thorough research was conducted on data bases like ERIC, jstor and EBSCOhost for GOs using the following descriptors: advance organizers, graphic organizers, visual displays or diagrams, cognitive mapping, concept mapping, knowledge maps, reading comprehension and reading strategies. At the same time, citations from articles and reviews were used.

The aim of this study is to summarize what research findings reveal about the effectiveness of GOs on deriving meaning from texts. It relates their use to the facilitation of reading comprehension skills, suggests ways of integrating them in reading lessons and touches on the issue of strategy instruction in language learning. Before focusing on research findings, a brief reference is made to the concepts of reading comprehension skill and reading strategies, the theoretical and historical foundations of GOs, and the types of GOs.

\section{Theoretical Framework}

Reading, a critical aspect of literacy, is regarded as an interaction between the reader and the text (Alderson \& Urquhart, 1984). Moreover, reading is purposeful and requires active involvement on behalf of the readers, as readers have specific goals to achieve, when reading a text (Koda, 2005). Though early attempts of reading instruction mainly emphasize on stu- dents' ability to decode and learn how to read, radically there is a shift in the reading process putting the emphasis on comprehension and text learning. However, there are a number of students who have difficulties in text comprehension and successful task completion, especially when they encounter difficult and long passages. Learners, particularly the struggling ones, can be actively involved in reading and derive meaning from written texts using reading comprehension strategies. Among the various reading strategies, graphic strategies are considered to approach reading differently from the traditional, linear text presentation (Chang, Sung, \& Chen, 2002).

GOs have received great attention and concern among general and special education researchers, as they depict a variety of relationships and structures in a single display (Chmielewski \& Dansereau, 1998). Throughout the years a lot of researchers have offered their own definitions. A simple and widespread definition is that GOs are "visual representation of information in the text” (Jiang \& Grabe, 2007: p. 34). Katayama, Robinson, Devaney, and Dubois (1997) consider GOs to be spatial displays of text information that can be given to students as study aids to accompany texts and communicate both vertical, hierarchical concept relations and horizontal, coordinate concept relations. Moreover, Alvermann regards GOs as "a type of advance organizers that activates a reader's prior knowledge and depicts the organizational pattern of a reading selection by schematically representing key vocabulary terms” (1981b: p. 4). Having a closer look at the above definitions we can infer that they have some things in common: 1) GOs consist of words; 2) they indicate relations among concepts by using spatial arrangements of the information in the text; 3) they depict the organizational plan of the text (Stull \& Mayer, 2007); and 4) GOs can be deployed in different kinds of texts (both narrative and expository texts). According to literature, a variety of terms is used to refer to GOs, such as visual displays, graphic(al) displays/representations, graphics, tree diagrams, structured over- 
views, network representations, adjunct displays/aids to name some of the most common.

\section{Origin of Graphic Organizers}

GOs, originally called advance organizers and then structured overviews, were primarily initiated by Richard Barron (Barron, 1969) but have their root in Ausubel's work. According to Ausubel's cognitive theory of meaningful verbal learning, the use of advance organizers enhances students' learning and retention of unfamiliar but meaningful materials (Ausubel, 1960). He assumed that the new information is acquired when it is linked to the learners' already existing cognitive structure (1968). Therefore, the purpose of the organizer is to activate students' prior knowledge and relate the new material to the previously stored information providing optimal anchorage and rendering the new material more familiar and meaningful (Ausubel, 1960), which is consistent with the schema theory (Anderson \& Pearson, 1984). According to the schema theory, our mind is composed of cognitive structures (schemata) of knowledge, known as prior or background knowledge, which accept and assimilate the newly acquired information in order to enhance learning and retention of information. One has comprehended a text when s/he has found a "mental home” for the information in the text or has altered an existing one in order to accommodate the new knowledge (Anderson \& Pearson, 1984). Researchers have relied on Ausubel's advance organizer concept to elaborate on the use of structured overviews or outlines as a strategy, which are used to enhance learners' conceptual organization before reading the passage (Barron, 1969; Earle \& Barron, 1973; Estes, Mills, \& Barron, 1969). These early studies were the foundation for the use of structured overviews with key vocabulary represented in a text to provide a conceptual framework prior to text reading.

\section{Types of Graphic Organizers}

Throughout literature, there are several types of GOs that use different conventions to communicate information and are classified in various ways. Vekiri (2002) in her review verifies the above statement, meaning that there is no consistency in the classification system of GOs and, as a result, the same terms may be used with different meanings from one study to another. In this paper, an attempt is made to refer to the most widely used GOs in literature. Although the various types of GOs are used to foster learning from different kinds of texts, they differ from each other in appearance and the types of relationships displayed.

\section{Story Maps}

One type of GOs mainly used in narrative texts is the story mapping. Story maps call students' attention to the main elements of stories, such as characters, time, setting, plot (problem, actions, outcomes) and visually represent key information in narrative texts using a specific structure (Boulineau, Force, Hagan-Burke, \& Burke, 2004). At the same time, they highlight significant relations within a story, which in turn leads to a deeper understanding (Gardill \& Jitendra, 1999). They can be used before reading a passage to activate students' prior knowledge, link what they read to their background knowledge structure, develop a purpose for their reading; while reading a passage to guide them through texts, help them monitor comprehension and after reading a passage to facilitate summarization of the most important ideas (Boulineau et al., 2004; Davis, 1994; Gardill \& Jitendra, 1999). Research supports that story maps are a promising type of GOs, which can improve students' reading comprehension (Boulineau et al., 2004; Dimino, Taylor, \& Gersten, 1995; Gardill \& Jitendra, 1999; Idol, 1987; Idol \& Croll, 1987; Singer \& Donlan, 1983; Vallecorsa \& de Bettencourt, 1997) (Figure 1).

Therefore, story maps are used to facilitate comprehension of narrative texts, whereas the other types of GOs are mainly used to enhance comprehension of expository texts, which pose more challenges to students, as they may contain unfamiliar vocabulary, complex relations, and structures and are often more information driven making the text dense in information and weak in comprehensibility (Kim, Vaughn, Wanzek, \& Wei, 2004).

\section{Matrix}

Another type of GOs, which is mainly used in expository texts, is matrix. Matrix was firstly investigated by Schwartz and his colleagues (Schwartz \& Fattaleh, 1972) and was later advanced by Kiewra and his colleagues (Kiewra, DuBois, Christian, \& McShane, 1988; Kiewra et al., 1991). It is a kind of input

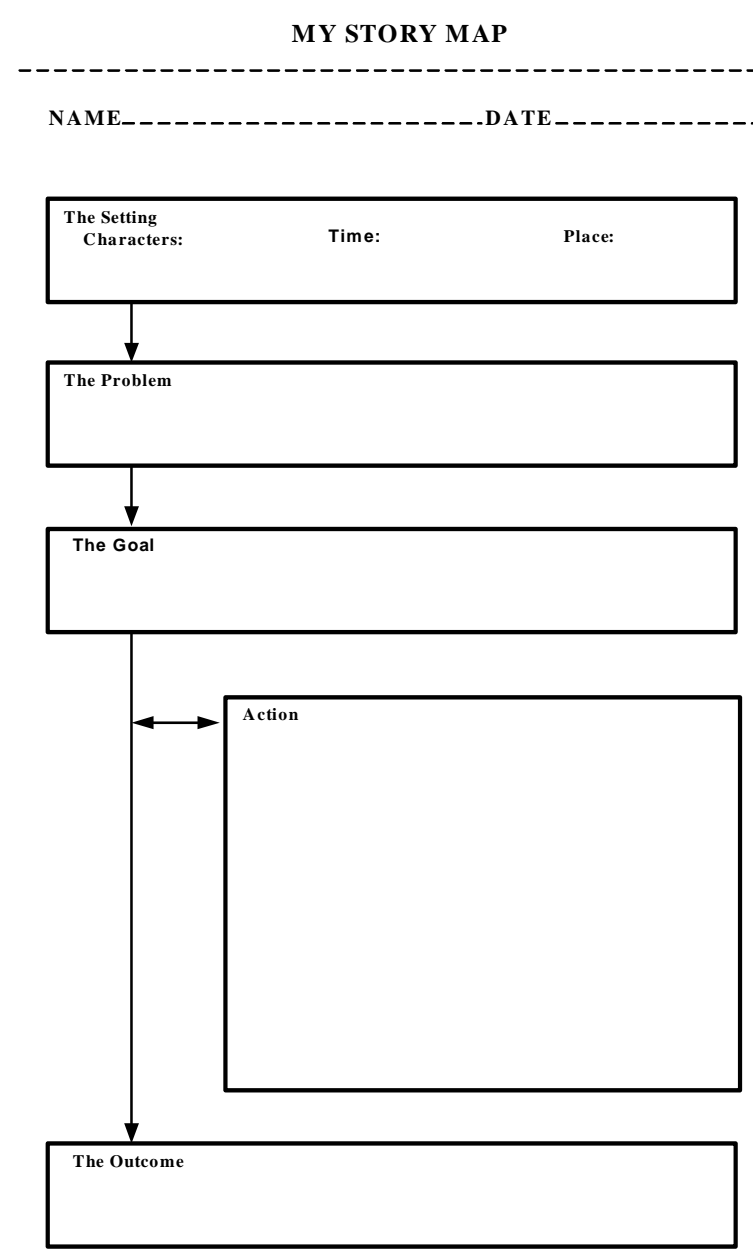

Figure 1.

Story map (Idol, 1987). 
table, which confines the sum of the desired information within its square (Graney, 1992; Kang, 2004). It is used to delineate important categories or relationships and depict similarities and disparities between two or more people, things, places or events (Graney, 1992; Jones, Pierce, \& Hunter, 1989). In order to design a matrix, learners need to identify which main aspects they wish to focus on and what types of relationships they wish to highlight (Graney, 1992). Matrix has the additional advantage of presenting concept relations both hierarchically/vertically and horizontically in a two-dimensional form facilitating the extraction of information, as it is located closer together than in texts (Kiewra, Kauffman, Robinson, Dubois, \& Stanley, 1999; Robinson \& Skinner, 1996). Therefore, its main purpose is to communicate comparisons among concepts and coordinate concept relations (Robinson \& Kiewra, 1995). Research has shown consistent effects favoring the use of matrix to locate relations and answers to questions and boost relational learning (Kiewra et al., 1999; Robinson \& Schraw, 1994; Robinson \& Skinner, 1996) (Figure 2).

\section{Semantics Maps}

Semantic maps are web-like organizers. Mind maps, spider maps or sunbursts are some of the terms that are used to refer to semantic maps. They look "like a sun or star with rays emanating from it, as they consist of a circle with lines radiating from the circle" (Graney, 1992: p. 164). They are diagrams that can be used to represent words, ideas, or other items linked to and arranged around a central key word or idea of the text and depict relationships of the different components of an idea to the main idea, that is of the part to the whole (Graney, 1992; Iranmehr, 2011). Namely, semantic maps place the main idea in the center around which relevant notions or sub-concepts are linked. Concurrently, they offer an overview of key vocabulary and concepts providing a link between what students know and what will learn and read, a type of a brainstorming activity mainly used before reading a passage to stimulate students' background cognitive structure and assess their knowledge in terms of the specific topic (Vaughn \& Edmonds, 2006). The development of semantic maps is based on the schema theory (Anderson \& Pearson, 1984). According to a research synthesis conducted by Kim et al. (2004), the use of semantic organizers enhances students' comprehension skills (Figure 3).

\section{Concept Maps}

One kind of graphic device that can affect learners' processing of expository texts is the cognitive/concept map. The development of concept maps is credited to Novak (Novak, 1990; Novak, 1991; Novak \& Musonda, 1991), who was based on Ausubel's (1968) assimilation theory of cognitive learning. According to Novak and Cañas (2008), they include concepts, usually enclosed in circles or boxes, and relationships between concepts indicated by a connecting line linking two concepts, while there are words on the line, referred to as linking words or phrases, which specify the relationship between the two concepts. Early maps did not include labels on the lines, whereas later labels on the lines were regarded as necessary, because even experts could see different meanings between the same two concepts on a map (Novak et al., 1983). Another characteristic of concept maps is that they indicate hierarchical representation of concepts usually organized with the most

\begin{tabular}{|c|l|l|l|}
\hline \multicolumn{2}{|c|}{ Name 1 } & & \\
\hline Attribute 1 & & & \\
\hline Attribute 2 & & & \\
\hline Attribute3 & & & \\
\hline
\end{tabular}

Figure 2.

Compare/contrast matrix (Kiewra et al., 1999).

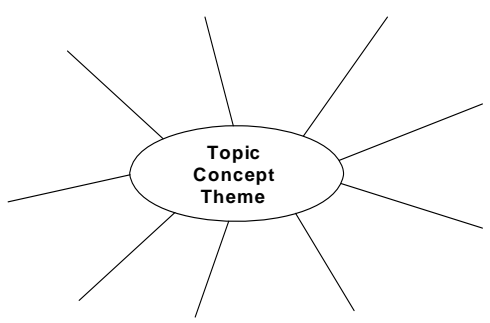

Figure 3.

Semantic map (Graney, 1992).

general, most inclusive idea at the top of the map, with successively less general, less inclusive concepts in appropriate subordinate positions (Novak, 1990; Novak \& Cañas, 2008). They can also represent multiple relationship types among concepts students would likely encounter in texts, such as comparative, causative, explanatory, sequential facilitating reading comprehension (Oliver, 2009). As their primary function is to focus on the selection of the main ideas (key words) of the text, connecting these concepts using relation links and displaying the major framework of the text, concept maps are a useful tool to represent knowledge in any discipline contributing to organizing, understanding and recalling new material (Chalarut \& DeBacker, 2004; Chang et al., 2002; Novak, 1990; Oliver, 2009; Schmid \& Telaro, 1990). A current trend in concept maps emphasizes on an electronic version (Canas et al., 2001; Novak \& Canas, 2008) (Figure 4).

\section{Knowledge Maps}

Another similar graphic organizer is the knowledge map. Knowledge mapping emerged from Dansereau's work (Chmielewski \& Dansereau, 1998; Hall, Dansereau, \& Scaggs, 1992; McCagg \& Dansereau, 1991). A knowledge map is a two-dimensional graphical display presenting information in the form of node-link-node assemblies, which contains key ideas and specifies the relationships between nodes (McCagg \& Dansereau, 1991). In addition, the nodes of a knowledge map depict conceptual information in the form of simple, verbal propositions and each link simultaneously has an arrowhead to indicate directionality (McCagg \& Dansereau, 1991). Knowledge maps also emphasize on the way concepts and ideas in a body of information are related to an overall structure (Chmielewski \& Dansereau, 1998). Studying knowledge maps consistently leads to better delayed recall of macro level ideas than merely studying texts (Amer, 1994; Chmielewski \& Dansereau, 1998; McCagg \& Dansereau, 1991). Conclusive results are provided by a review, which indicates that students, especially the less skilled ones, recall more central ideas, when they study a knowledge map (O’Donnell, Dansereau, \& Hall, 2002). However, as there is confusion in the classification of GOs throughout lite- 


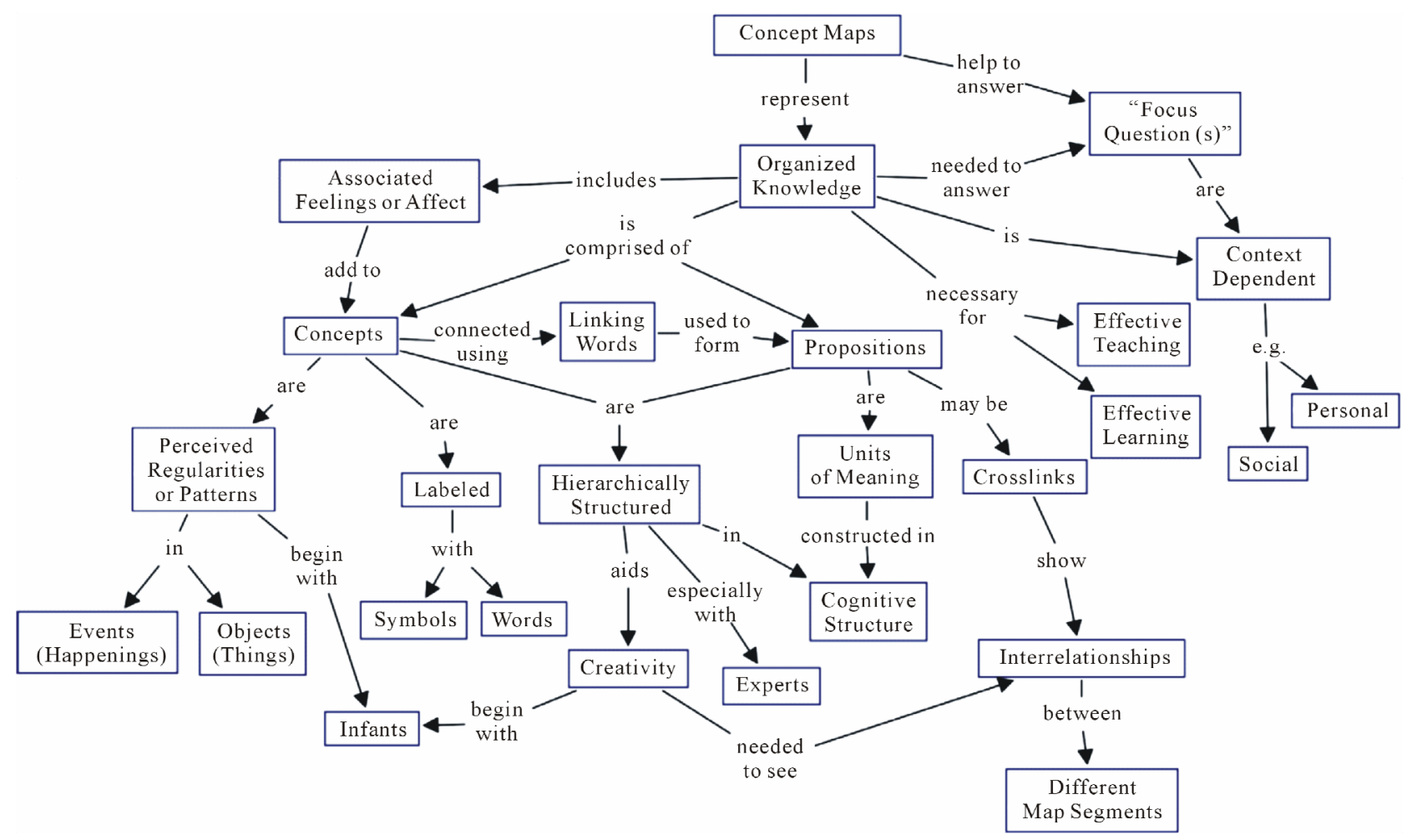

Figure 4.

Concept map (Novak \& Cañas, 2008).

rature, knowledge maps are often related to concept maps. It should be pointed out that knowledge maps differ from other similar representations, such as concept maps, in the deliberate use of a set of labeled links that connect ideas and have arrowheads to establish directionality among ideas (O’Donnell et al., 2002) (Figure 5).

\section{Tree Diagrams}

Tree diagrams/tree structures/network trees, which belong to hierarchical organizers, visually portray the main ideas of a text and establish the multiple relations among the different elements that exist in a passage, such as general to specific or specific to general through hierarchically describing the relationships of the different elements of the text (Graney, 1992). Namely, tree diagrams communicate super ordinate-subordinate or hierarchical concept relations, which is the defining feature of a hierarchy (Robinson \& Kiewra, 1995; Robinson \& Skinner, 1996). More often than not, they are used to describe family trees, the construction of a sentence, the structure of societies, classes, institutions, taxonomies, and various hierarchical models (Guri-Rozenblit, 1989). Research supports the implementation of tree diagrams to boost comprehension and recall of main ideas (Guri-Rozenblit, 1989) (Figure 6).

\section{Venn Diagrams}

The Venn diagram belongs to linear organizers. It is composed of two or more overlapping circles used as a framework to make comparisons between two or more concepts (Kang, 2004). It is named after John Venn (Venn, 1880), who used it in maths (Figure 7).

\section{Effectiveness of Graphic Organizers: Research Findings}

The findings of studies concerning the effectiveness of GOs on students' comprehension and text learning are thoroughly discussed in this section. Namely, first language (L1) and second language (L2) studies yielding both consistent and inconsistent results in terms of the use of GOs in relation to text learning are included. Research evidence coming from studies conducted with students with Learning Disabilities (LD) is also commented. Concurrently, ways of incorporating GOs in classrooms are recommended and further exploration of GOs is suggested.

\section{Consistent Findings in First Language Graphic Organizer Research}

Researchers have attempted to enhance learners' comprehension skills of both narrative and expository texts through the use of GOs, which visually represent the main ideas or structure of texts. The experimental studies of GOs advocate their use and most of them include at least an experimental/intervention (GO) and a control group as well as a pre and post testing design. To begin with, several studies in L1 demonstrate that emphasis on GO training is inextricably linked with improvement in comprehension skills, as they help students identify, organize and recall the main ideas of a text (Alvermann \& Boothby, 1986; Armbruster, Anderson, \& Ostertag, 1987; Berkowitz, 1986; Chang et al., 2002; Chmielewski \& Dansereau, 1998; Geva, 1983; Guri \& Rozenblit, 1989; Horton, Lovitt, \& Bergerud, 1990; Idol, 1987; Kiewra et al., 1999; Oliver, 2009; Robinson et al., 2006). Robinson and Skinner (1996), in particular, demon- 


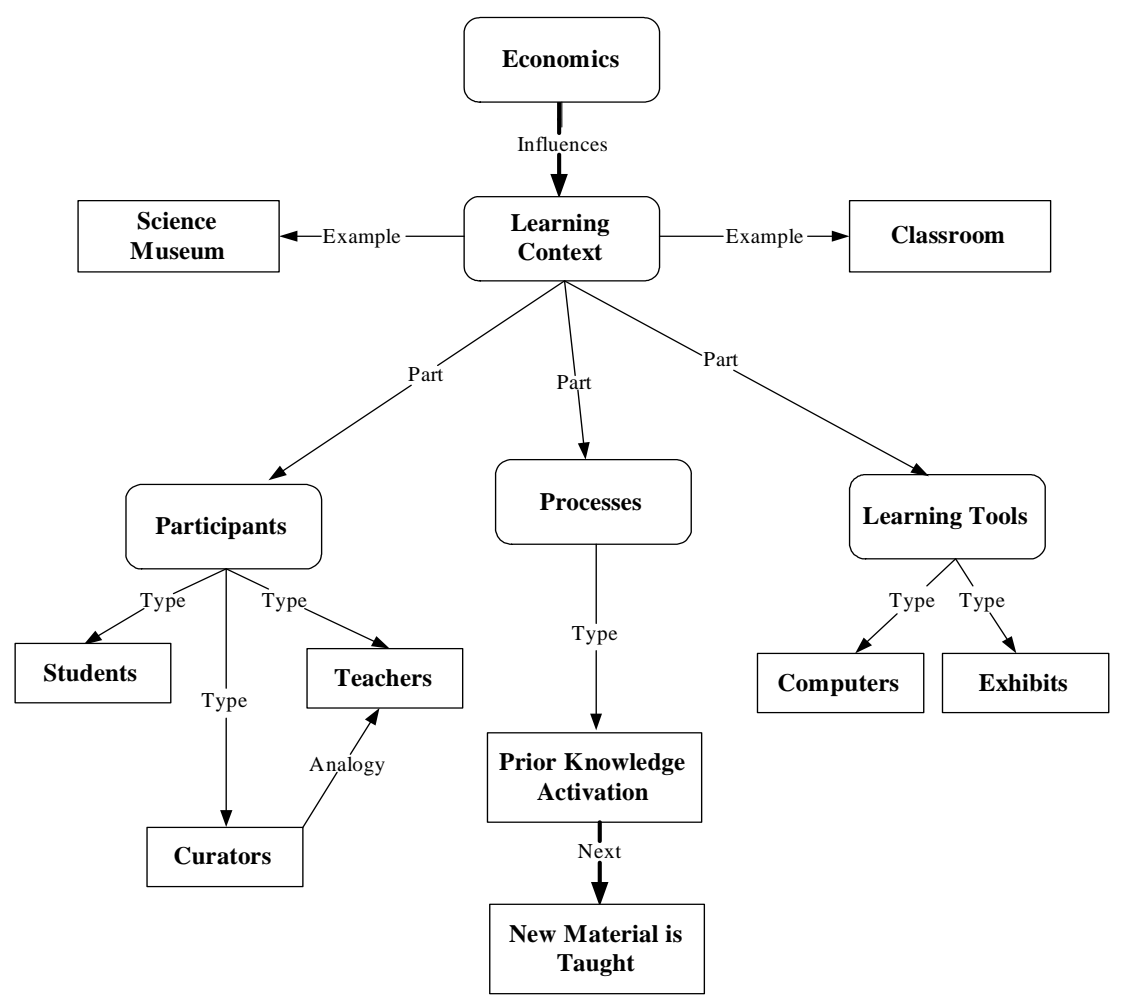

Figure 5.

Knowledge map (O’Donnell et al., 2002).

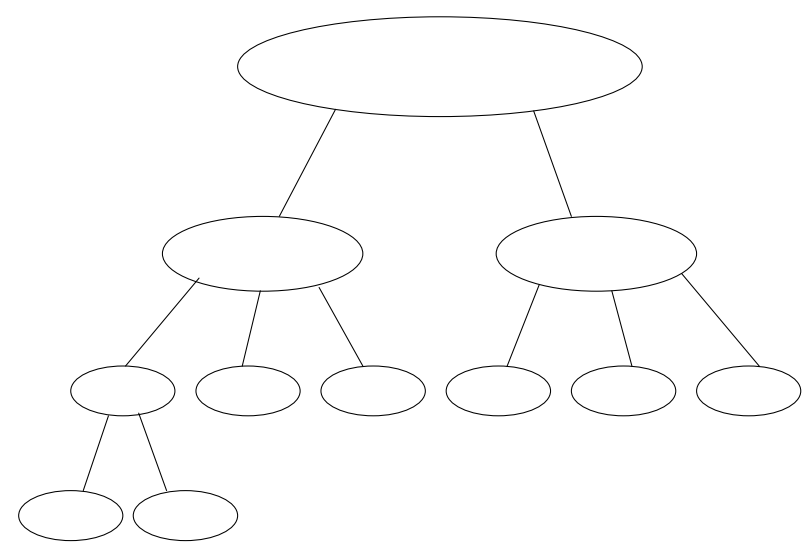

Figure 6.

Tree diagram (Jones et al., 1989).

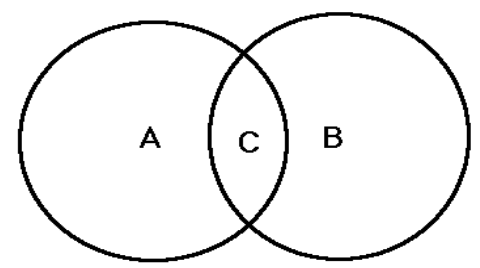

Figure 7.

Venn diagram (Venn, 1880).

strate that GOs facilitate students' skill in locating specific information quickly in order to answer comprehension questions, while Robinson and Kiewra (1995) highlight that, when learners study GOs, they can learn hierarchical and coordinate relations thus becoming more successful in integrating this knowledge into writing. Concurrently, a large body of research on the use of GOs in the reading process focuses on their function as a visual map of the actual text structure (e.g., compare/ contrast, problem/solution, cause/effect, description). Namely, research supports that GOs raise students' awareness of the various text structures and facilitate the identification of this higher level organization, a critical factor in comprehension (Alvermann, 1981, Alvermann \& Boothby, 1986; Armbruster, Anderson, \& Meyer, 1991; Armbruster et al., 1987; Berkowitz, 1986; Geva, 1983; Guri-Rozenblit, 1989; Oliver, 2009). Furthermore, research indicates that GOs training enhances learners' summarization abilities (Armbruster et al., 1987; Chang et al., 2002). Throughout literature, it is also evident that poor or low ability students are those who benefit most from GOs training (Balajthy \& Weisberg, 1990; Geva, 1983; O’Donnell et al., 2002; Schmid \& Telaro, 1990).

At the same time, in a meta-analysis carried out by Moore and Readence (1984) learners treated with GOs outperformed learners in control groups ascertaining that GOs produce a small but positive effect on text learning. In addition, Vekiri (2002) and O’Donnell et al. (2002) in their reviews provide supportive results regarding the use of GOs as scaffolds for concept relation, text learning and central ideas recalling respectively. In more recent reviews, Nesbit and Adesope (2006) focusing on concept and knowledge maps conclude that the specific types of maps are more effective for retaining knowledge than reading texts or attending lectures, while Jiang and Grabe (2007) provide strong evidence for the effectiveness of GOs representing the discourse structures of texts on the im- 
provement in comprehension of reading materials.

Allowing for the visual nature of GOs and the reduction of linguistic load and task complexity that GOs offer, a large body of research on GOs focuses on LD students, who have difficulties in deriving meaning from written texts. Overall, research suggests that GOs can mainly help students with LD or low ability students comprehend and recall important information in a text, something which holds true for the various learning strategies (Boulineau et al., 2004; Gardill \& Jitendra, 1999; Idol, 1987; Idol \& Croll, 1987; Horton et al., 1990; Vallecorsa \& de Bettencourt, 1997). Concurrently, Kim et al., (2004) and Gajria, Jitendra, Sood, and Sacks (2007) lend support for the effectiveness of GOs on boosting comprehension skills. The findings of a more recent meta-analytic review conducted by Dexter, Park, and Hughes (2011) also corroborate the facilitative effects of GOs on increased vocabulary knowledge and comprehension gains.

\section{Inconsistent Findings in First Language Graphic Organizer Research}

Notwithstanding the supportive findings of a large body of literature, there are some studies that yield conflicting results regarding the use of GOs. Namely, Alvermann (1981) did not manage to fully support the effectiveness of GOs on reading comprehension; Bean, Singer, Sorter, and Frazee (1986) and Simmons et al. (1988) consider GO training to be no more effective than outlining or traditional instruction for increasing students' comprehension and retention of text information. Moreover, Balajthy \& Weisberg (1990) fail to provide a statistically significant improvement in passage comprehension or summarization scores highlighting that GO training mostly favors lower ability groups. At the same time, Armbruster et al. (1991) and Davis (1994) provide inconclusive results concerning the effectiveness of GOs on text comprehension, as they found positive effects of GOs on text comprehension in one grade but no statistically meaningful difference in the other grade emphasized in their studies. Non-supportive results were also provided by Griffin, Malone, and Kameenui (1995). Concurrently, Rice (1994) and Griffin and Tulbert (1995) in their review found inconsistency in the research findings of GOs studies questioning the facilitative effects of GOs on text comprehendsion.

In terms of studies focusing on students with LD, Griffin, Simmons, and Kameenui (1991) as well as DiCecco and Gleason (2002) failed to provide consistent findings regarding the effectiveness of GOs on students' comprehension. Despite the non-supportive results of some studies, almost all researchers support that learners benefit from the implementation of GOs in classrooms in one way or another (e.g., Armbruster et al., 1991; Balajthy \& Weisberg, 1990).

Taking all the above into account, we can draw the conclusion that, though some studies failed to yield positive results regarding the effectiveness of GOs, they constitute an instructional strategy used to assist students in learning from both informational and narrative texts. However, based on the information derived from previous research (Jiang \& Grabe, 2007), one critical factor that can affect the findings of the various studies is the length of training period. In other words, researchers assert that the length of instruction can be a significant variable in classroom studies in order to achieve strategy mastery accentuating the need for longer interventions (Al- vermann, 1981; Alvermann \& Boothby, 1986; Bean et al., 1986; Griffin et al., 1995; Schmid \& Telaro, 1990).

\section{Second Language Graphic Organizer Research}

Although there is evidence that a specific type of GOs, concept maps, is a useful strategy for English as a Second Language (ESL) students (Block, 1986; Carrell, Pharis, \& Liberto, 1989; Koumy \& Salam, 1999), few studies investigated the effectiveness of GOs on L2 reading comprehension. To be more precise, Tang (1992), who examined the relation of graphic representation of text structure to comprehension with ESL students, indicated great gains in the amount of information recalled. Furthermore, Amer (1994) probing into the effect of deploying knowledge maps and underlining on students' comprehension of English scientific texts found that both experimental groups outperformed the control group on summarization, while the knowledge map group performed slightly better. Another study (Koumy \& Salam, 1999) focusing on the effects of three semantic mapping strategies (teacher-initiated, student mediated, teacher-student interactive mapping) on comprehension of ESL students revealed that learners in the teacher-student interactive mapping group scored significantly higher than the other two groups. Additionally, Chularut and DeBacker (2004) demonstrated facilitative effects of the use of GOs on ESL students' text learning, self-efficacy and self-monitoring; Suzuki, Sato, and Awazu (2008) exploring the advantage of the spatial graphic representation of an English sentence over a linear sentential representation supported that the spatial graphic display enhanced ESL readers' comprehension of sentences more than the sentential display did.

\section{Ways of Using Graphic Organizers-Instructional Implications}

Based on research (Jiang \& Grabe, 2007), GOs can be used in education in different ways in all reading stages producing different effects on comprehension. The instructional procedures vary depending on the position of GOs in relation to reading (pre-reading, post reading stage) and the constructor of GOs (teacher-constructed, student-constructed, teacher/student constructed). Namely, GOs are used in the pre-reading stage usually as a brainstorming activity to generate ideas, activate learners' prior knowledge, connect what the students know with new information and provide a purpose for reading. Davis (1994) and Simmons et al. (1988), who focused on a pre-reading GO, provide facilitative effects of the use of GOs prior to text reading on students' comprehension. However, the instructional position of GOs shifted from the pre-reading to the postreading position (Rice, 1994). As for the post-reading stage, GOs are used in order to assess the degree of students' understanding and enhance recall, retention and summarization of main ideas, which can often function as a plan leading to writing tasks. In fact, research demonstrates that GOs are more effective, when used in the post-reading than in the pre-reading stage (Griffin \& Tulbert, 1995; Moore \& Readence, 1984).

Additionally, the constructor of GOs exerts influence on comprehension (Jiang \& Grabe, 2007), as GOs can be student, author or teacher created and teacher/student created with the goal of assisting students in learning from texts. To put it differently, some researchers report that teacher-initiated GOs result in improved reading comprehension (Alvermann, 1981; Idol, 1987). Another body of research yields positive results 
regarding GOs generated or even simply partially completed by students emphasizing on students' active involvement in the learning process (Berkowitz, 1986; McCagg \& Dansereau, 1991). Concurrently, other studies have shown that the map construction group did not fare better than the control group (Chang et al., 2002; Stull \& Mayer, 2007) attributing this result to the cognitive load theory, according to which a heavy extraneous cognitive load that the instructional procedures often imposed is to blame for interfering with learning (Stull \& Mayer, 2007; Sweller, van Merrienboer, \& Paas, 1998). A third group of researchers, support the effectiveness of teacher-student constructed GOs on text learning (Koumy \& Salam, 1999).

Although the majority of studies throughout literature include GOs presented on paper, there is a new trend focusing on an electronic version of GOs, in particular concept maps (Canas et al., 2001; Novak \& Canas, 2008). A few researchers have trained students in using concept map software (Cmap Tools) and have provided positive effects favoring computer-based maps in their studies (Chang, Sung, \& Chen, 2001; DeSimone, Schmid, \& McEwen, 2001; Oliver, 2009). In this way, the strength of concept maps co-exists with technology familiarizing students with the new technological achievements, the internet and the World Wide Web.

Based on research, teachers should adopt the use of GOs as a reading strategy in the teaching and learning of languages in order to help students enhance text comprehension. Namely, teachers should familiarize learners with GO studying and aim at training them in constructing GOs and independently implementing them in and out of classrooms; they should model how to construct GOs, explain when and why students should use GOs, provide students with opportunities to guided practice and feedback, gradually shifting responsibility from teacher to students, until students become proficient at using this strategy in independent learning settings. At the heart of this recommendation lies the concept of strategic approach to reading, which focuses on autonomous learners, able to use strategies during their independent study (Cohen, 2007; Palincsar \& Brown, 1984; Pressley, El-Dinary, Gaskins, Schuder, Bergman, Almasi, \& Brown, 1992).

\section{Room for Research}

According to literature, a body of research has yielded conflicting results regarding the effectiveness of GOs on learners' retention and comprehension of text information (Alvermann, 1981; Armbruster et al., 1991; Balajthy \& Weisberg, 1990; Griffin et al., 1991; Griffin et al., 1995; Griffin \& Tulbert, 1995; Simmons et al., 1988). Allowing for the above non-supportive findings of studies, room for research is left in further exploring the effectiveness of GOs as a reading strategy, especially in the language teaching courses. Jiang and Grabe (2007) strongly support that instead of being discouraged and frustrated in the inconsistency of the above findings, it is important to view the issue from a different perspective and start further exploring the specific area. Furthermore, research that involves longer intervention is required, as most studies spend a few hours or a couple of days on GO training, because students need extended instructional time to be exposed to practice in GOs in order to achieve strategy mastery and be able to use them independently in new learning situations, which is in accordance with previous research findings (Alvermann, 1981; Alvermann \& Boothby, 1986; Bean et al., 1986; DiCecco \& Gleason, 2002; Jiang \& Grabe, 2007; Kim et al., 2004; Moore \& Readence, 1984; Sch- mid \& Telaro, 1990). Future research should also assess longterm retention, maintenance and transfer of training effects of GOs on comprehension skills allowing a month or more to pass, since maintenance is the most desired outcome of strategy training. In fact, the majority of studies investigate immediate influence of GOs on text learning including only a posttest, while lacking a follow-up study and saying little about what happens afterwards, which concurs with previous literature (Chang et al., 2002; Moore \& Readence, 1984). At the same time, further exploration is needed at middle or secondary grades, as most of the studies conducted in this area focus on elementary (e.g., Alvermann \& Boothby, 1986; Armbruster et al., 1991; Armbruster et al., 1987; Berkowitz, 1986; Chang, 2002; Davis, 1994; Griffin et al., 1995; Oliver, 2009; Simmons et al., 1988) or college students (e.g., Balajthy \& Weisberg, 1990; Chmielewski \& Dansereau, 1998; Geva, 1983; Guri \& Rozenblit, 1989; Katayama et al., 1997; Kiewra et al., 1999; Robinson \& Katayama, 2006; Robinson \& Kiewra, 1995; Robinson \& Skinner, 1996). Last but not least, based on research on GOs, there is an obvious dearth of GO studies in second or foreign languages, as most of GO studies focus on first or native language learners, which is consistent with previous findings (Jiang \& Grabe, 2007; Nesbit \& Adesope, 2006).

By and large, further GO investigation is needed to define the impact of the different types of GOs on students' comprehension or summarization skills, especially in the field of teaching and learning of foreign languages, comparing GOs interventions with traditional instruction in reading comprehension or with other comprehension strategies (DiCecco \& Gleason, 2002; Iranmehr, 2011; Kim et al., 2004). Although significant progress has been made in examining how to design and implement visual aids in classrooms, our understanding of this issue is still under development (Vekiri, 2002).

\section{Some Final Thoughts on Graphic Organizers}

In a nutshell, according to literature review, GOs have been successfully deployed with students with or without learning disabilities before, during and after reading texts. As visual scaffolds, they are conducive on assisting students in activating prior knowledge, gaining an insight into text structure, identifying as well as connecting the main ideas of a text resulting thus in better recall and retention of information. Allowing for the benefits of GOs, teachers should implement this strategy in classrooms and train students in using it helping them become independent and self-regulated learners, especially after longterm interventions. However, the above findings should be interpreted with some caution, as some studies have yielded inconsistent results regarding the use of GOs, which requires further research, particularly on L2 classrooms.

\section{Acknowledgements}

This study consists part of a broader research on the contribution of strategy instruction to the improvement in elementary students' reading comprehension, which is co-financed by the European Union (European Social Fund-ESF) and the Greek national funds through the Operational Program "Education and Lifelong Learning” of the National Strategic Reference Framework (NSRF)-Research Funding Program: HERACLEITUS II. Investing in knowledge society through the European Social Fund. 


\section{REFERENCES}

Alderson, C., \& Urquhart, A. H. (1984). Introduction: What is reading? In C. Alderson, \& A. H. Urquhart (Eds.), Reading in a foreign language (pp. 16-28). London \& New York: Longman.

Alvermann, D. E. (1981). The compensatory effect of graphic organizers on text structure. ERIC Document Reproduction Service, ED. 208 019.

Alvermann, D. E., \& Boothby, P. R. (1986). Children's transfer of graphic organizer instruction. Reading Psychology, 7, 87-100. doi:10.1080/0270271860070203

Amer, A. A. (1994). The effect of knowledge map and underlining training on the reading comprehension of scientific texts. English Specific Purposes, 13, 35-45. doi:10.1016/0889-4906(94)90023-X

Anderson, R. C., \& Pearson, P. D. (1984). A schema-theoretic view of basic processes in reading comprehension. In P. D. Pearson (Ed.), Handbook of reading research (pp. 255-291). New York: Longman.

Armbruster, B. B., Anderson, T. H., \& Meyer, J. L. (1991). Improving content-area reading using instructional graphics. Reading Research Quarterly, 26, 393-416. doi:10.2307/747895

Armbruster, B. B., Anderson, T. H., \& Ostertag, J. (1987). Does text structure/summarization instruction facilitate learning from expository text? Reading Research Quarterly, 22, 331-346. doi:10.2307/747972

Ausubel, D. P. (1960). The use of advance organizers in learning and retention of meaningful material. Journal of Educational Psychology, 51, 267-272. doi:10.1037/h0046669

Ausubel, D. P. (1968). Educational psychology: A cognitive view. New York: Holt, Rinehart, \& Winston.

Balajthy, E., \& Weisberg, R. (1990). Effects of reading ability, prior knowledge, topic interest, and locus of control on at-risk college students' use of graphic organizers and summarizing. ERIC Document Reproduction Service, ED. 325838.

Barron, R. (1969). The use of vocabulary as an advance organizer. In H. L. Herber, \& P. L. Sanders (Eds.), Research in reading in content areas: First year report (pp. 29-39). Syracuse, NY: Syracuse University, Reading and Language Arts Center.

Bean, T. W., Singer, H., Sorter, J., \& Frazee, C. (1986). The effect of metacognitive instruction in outlining and graphic organizer construction on students' comprehension in a tenth-grade world history class. Journal of Reading Behavior, 18, 153-169.

Berkowitz, S. J. (1986). Effects of instruction in text organization on sixth-grade students' memory for expository reading. Reading Research Quarterly, 21, 161-178. doi:10.2307/747843

Block, E. (1986). The comprehension strategies of second language readers. TESOL Quarterly, 20, 463-494. doi:10.2307/3586295

Boulineau, T., Force, C., Hagan-Burke, S., \& Burke, M. D. (2004). Use of story-mapping to increase the story grammar text comprehension of elementary students with learning disabilities. Learning Disability Quarterly, 27, 105-121. doi:10.2307/1593645

Cañas, A. J., Ford, K. M., Novak, J. D., Hayes, P., Reichherzer, T., \& Suri, N. (2001). Online concept maps: Enhancing collaborative learning by using technology with concept maps. The Science Teacher, 68, 49-51.

Carrell, P., Pharis, B. G., \& Liberto, J. C. (1989). Metacognitive strategy training for ESL reading. TESOL Quarterly, 23, 647-673. doi: $10.2307 / 3587536$

Chularut, P., \& DeBacker, T. K. (2004). The influence of concept mapping on achievement, self-regulation, and self-efficacy in students of English as a second language. Contemporary Educational Psychology, 29, 248-263. doi:10.1016/j.cedpsych.2003.09.001

Chang, K. E., Sung, Y. T., \& Chen, S. F. (2001) Learning through computer-based concept mapping with scaffolding aid. Journal of Computer Assistance Learning, 17, 21-33. doi:10.1111/j.1365-2729.2001.00156.X

Chang, K. E., Sung, Y. T., \& Chen, I. D. (2002). The effect of concept mapping to enhance text comprehension and summarization. Journal of Experimental Education, 71, 5-23. doi:10.1080/00220970209602054

Chmielewski, T., \& Dansereau, D. F. (1998). Enhancing the recall of text: Knowledge mapping training promotes implicit transfer. Journal of Educational Psychology, 90, 407-413. doi:10.1037/0022-0663.90.3.407

Cohen, A. D. (2007). Coming to terms with language learner strategies: Surveying the experts. In A. D. Cohen, \& E. Macaro (Eds.), Language learning strategies: Thirty years of research and practice (pp. 29-45). Oxford: Oxford University Press.

Davis, Z. T. (1994). Effects of prereading story mapping on elementary readers' comprehension. Journal of Educational Research, 87, 353360. doi:10.1080/00220671.1994.9941266

DeSimone, C., Schmid, R. F., \& McEwen, L. A. (2001) Supporting the learning process with collaborative concept mapping using computer-based communication tools and processes. Education Research Evaluation, 7, 263-283. doi:10.1076/edre.7.2.263.3870

Dexter, D. D., Park, Y. J., \& Hughes, C. A. (2011). A meta-analytic review of graphic organizers and science instruction for adolescents with learning disabilities: Implications for the intermediate and secondary science classroom. Learning Disabilities Research \& Practice, 26, 204-213. doi:10.1111/j.1540-5826.2011.00341.x

DiCecco, V. M., \& Gleason, M. M. (2002). Using graphic organizers to attain relational knowledge from expository text. Journal of Learning Disabilities, 35, 306-320. doi:10.1177/00222194020350040201

Dimino, J. A., Taylor, R. M., \& Gersten, R. M. (1995). Synthesis of the research on story-grammar as a means to increase comprehension. Reading \& Writing Quarterly: Overcoming Learning Difficulties, 11, 53-72.

Earle, R. A., \& Barron, R. (1973). An approach for teaching vocabulary in content subjects. In H. L. Herber, \& R. F. Barron (Eds.), Research in reading in content areas: Second year report (pp. 84-100). Syracuse, NY: Syracuse University, Reading and Language Arts Center.

Estes, T. H., Mills, D. C., \& Barron, R. F. (1969). Two methods of introducing students to a reading-learning task in two content subjects. In H. L. Herber, \& P. L. Sanders (Eds.), Research in reading in content areas: First year report (pp. 40-48). Syracuse, NY: Syracuse University, Reading and Language Arts Center,.

Gajria, M., Jitendra, A. K., Sood, S., \& Sacks, G. (2007). Improving comprehension of expository text in students with LD: A research synthesis. Journal of Learning Disabilities, 40, 210-225. doi:10.1177/00222194070400030301

Gardill, M. C., \& Jitendra, K. A. (1999). Advanced story map instruction: Effects on the reading comprehension of students with learning disabilities. Journal of Special Education, 33, 2-17. doi:10.1177/002246699903300101

Gersten, R., Fuchs, L. S., Williams, J. P., \& Baker, S. (2001).Teaching reading comprehension strategies to students with learning disabilities: A review of research. Review of Educational Research, 71, 279320. doi:10.3102/00346543071002279

Geva, E. (1983). Facilitating reading comprehension through flowcharting. Reading Research Quarterly, 18, 384-405. doi:10.2307/747375

Graney, M. J. (1992). A framework for using text graphing. System, 20, 161-167. doi:10.1016/0346-251X(92)90022-U

Griffin, C. C., Malone, L. D., \& Kameenui, E. J. (1995). Effects of graphic organizer instruction on fifth-grade students. Journal of Educational Research, 89, 98-107. doi:10.1080/00220671.1995.9941200

Griffin, C. C., Simmons, D. C., \& Kameenui, E. J. (1991). Investigating the effectiveness of graphic organizer instruction on the comprehension and recall of science content by students with learning disabilities. Reading and Writing Quarterly, 7, 355-376.

Griffin, C. C., \& Tulbert, B. L. (1995). The effect of graphic organizers on students' comprehension and recall of expository text: A review of the research and implications for practice. Reading and Writing Quarterly, 11, 73-89. doi:10.1080/1057356950110106

Guri-Rozenblit, S. (1989). Effects of a tree diagram on students' comprehension of main ideas in an expository text with multiple themes. Reading Research Quarterly, 24, 236-247. doi:10.2307/747866

Hall, R. H., Dansereau, D. E., \& Skaggs, L. P. (1992). Knowledge maps and the presentation of related information domains. Journal of $E x-$ perimental Education, 61, 5-18. doi:10.1080/00220973.1992.9943845

Hartley, J., \& Davies, I. K. (1976). Preinstructional strategies: The role of pretests, behavioral objectives, overviews and advance organizers. Review of Educational Research, 46, 239-265. doi:10.3102/00346543046002239

Horton, S. C., Lovitt, T. C., \& Bergerud, D. (1990). The effectiveness 
of graphic organizers for three classifications of secondary students in content area classes. Journal of Learning Disabilities, 23, 12-29. doi:10.1177/002221949002300107

Idol, L. (1987). Group story mapping: A comprehension strategy for both skilled and unskilled readers. Journal of Learning Disabilities, 20, 196-205. doi:10.1177/002221948702000401

Idol, L., \& Croll, V. (1987). Story mapping training as a means of improving reading comprehension. Learning Disability Quarterly, 109, 214-230. doi:10.2307/1510494

Iranmehr, A., Davari, H., \& Erfanie, S. M. (2011). The application of organizers as an efficient technique in ESP textbooks development. Theory and Practice in Language Studies, 1, 417-422. doi:10.4304/tpls.1.4.417-422

Jiang, X., \& Grabe, W. (2007). Graphic organizers in reading instructtion: Research findings and issues. Reading in a Foreign Language, 19, 34-55.

Jones, B., Pierce, J., \& Hunter, B. (1989). Teaching children to construct graphic representations. Educational Leadership, 46, 20-25.

Kang, S. (2004). Using visual organizers to enhance EFL instruction. JALT Journal, 58, 58-67.

Katayama, A. D., Robinson, D. H., Devaney, T., \& Dubois, N. F. (1997). The interaction of study materials and spaced review on transfer and relational learning. ERIC Document Reproduction Service, ED. 411 280.

Kiewra, K. A., DuBois, N. F., Christian, D., \& McShane, A. (1988). Providing study notes: A comparison of three types of notes for review. Journal of Educational Psychology, 80, 595-597. doi:10.1037/0022-0663.80.4.595

Kiewra, K. A., DuBois, N. F., Christian, D., McShane, A., Meyerhoffer, M., \& Roskelley, D. (1991). Note taking functions and techniques. Journal of Educational Psychology, 83, 240-245. doi:10.1037/0022-0663.83.2.240

Kiewra, K. A., Kauffman, D. F., Robinson, D. H., Dubois, N. F., \& Stanley, R. K. (1999). Supplementing floundering text with adjunct displays. Instructional Science, 27, 373-401. doi:10.1023/A:1003270723360

Kim, A., Vaughn S., Wanzek J., \& Wei, S. (2004). Graphic organizers and their effects on the reading comprehension of students with LD: A synthesis of research. Journal of Learning Disabilities, 37, 105118. doi:10.1177/00222194040370020201

Koda, K. (2005). Insights into second language reading: A cross-linguistic approach. Cambridge: Cambridge University Press.

Koumy, E., \& Salam, A. (1999). Effects of three semantic mapping strategies on EFL students reading comprehension. ERIC Document Reproduction Service, ED. 435193.

McCagg, E. C., \& Dansereau, D. F. (1991). A convergent paradigm for examining knowledge mapping as a learning and recall strategy. Journal of Educational Research, 84, 317-324. doi:10.1080/00220671.1991.9941812

Moore, D. W., \& Readence, J. E. (1984). A quantitative and qualitative review of graphic organizer research. Journal of Educational Research, 78, 11-17.

Nesbit, J. C., \& Adesope, O. O. (2006). Learning with concept and knowledge maps: A meta-analysis. Review of Educational Research, 76, 413-448. doi:10.3102/00346543076003413

Novak, J. D. (1990). Concept mapping: A useful tool for science education. Journal of Research in Science Teaching, 27, 937-949. doi:10.1002/tea.3660271003

Novak, J. D. (1991). Clarify with concept maps: A tool for students and teachers alike. Science Teacher, 58, 45-49.

Novak, J. D., \& Cañas, A. J. (2008). The theory underlying concept maps and how to construct and use them. URL (Last checked 13 December 2011).

http://cmap.ihmc.us/Publications/ResearchPapers/TheoryUnderlying ConceptMaps.pdf

Novak, J. D., \& Musonda, D. (1991). A twelve-year longitudinal study of science concept learning. American Educational Research Journal, 28, 117-153. doi:10.3102/00028312028001117

O’Donnell, A. M., Dansereau, D. F., \& Hall, R. H. (2002). Knowledge maps as scaffolds for cognitive processing. Educational Psychology Review, 14, 71-86. doi:10.1023/A:1013132527007

Oliver, K. (2009). An investigation of concept mapping to improve the reading comprehension of science texts. Journal of Science Education and Technology, 18, 402-414. doi:10.1007/s10956-009-9157-3

Palincsar, A. S., \& Brown, A. L. (1984). Reciprocal teaching of comprehension-fostering and comprehension-monitoring activities. Cognition and Instruction, 1, 117-175. doi:10.1207/s1532690xci0102_1

Pressley, M., El-Dinary, P. B., Gaskins, I., Schuder, T., Bergman, J. L., Almasi, J., \& Brown, B. (1992). Beyond direct explanation: Transactional instruction of reading comprehension strategies. Elementary School Journal, 92, 513-555. doi:10.1086/461705

Rice, G. E. (1994). Need for explanations in graphic organizer research. Reading Psychology, 15, 39-67. doi:10.1080/0270271940150103

Robinson, D. H., Katayama, A. D., Beth, A., Odom, S., Hsieh, Y., \& Vanderveen, A. (2006). Increasing text comprehension and graphic note taking using a partial graphic organizer. Journal of Educational Research, 100, 103-111. doi:10.3200/JOER.100.2.103-111

Robinson, D. H., \& Kiewra, K. A. (1995). Visual argument: Graphic organizers are superior to outlines in improving learning from text. Journal of Educational Psychology, 87, 455-467. doi:10.1037/0022-0663.87.3.455

Robinson, D. H., \& Schraw, G. (1994). Computational efficiency through visual argument: Do graphic organizers communicate relations in text too effectively. Contemporary Educational Psychology, 19, 399-415. doi:10.1006/ceps.1994.1029

Robinson, D. H., \& Skinner, C. H. (1996). Why graphic organizers facilitate search processes: Fewer words or computationally effective indexing? Contemporary Educational Psychology, 21, 161-180. doi:10.1006/ceps.1996.0014

Schmid, R. F., \& Telaro, G. (1990). Concept mapping as an instructional strategy for high school biology. Journal of Educational Research, 84, 78-85.

Schwartz, S. H., \& Fattaleh, D. L. (1972). Representation in deductive problem solving: The matrix. Journal of Experimental Psychology, 95, 343-348. doi:10.1037/h0033669

Simmons, D. C., Griffin, C. C., \& Kameenui, E. J. (1988). Effects of teacher-constructed pre- and post-graphic organizer instruction on sixth-grade science students' comprehension and recall. Journal of Educational Research, 82, 15-21.

Singer, H., \& Donlan, D. (1983). Active comprehension: Problem-solving schema with question generation for comprehension of complex short stories. Reading Research Quarterly, 17, 166-185. doi: $10.2307 / 747482$

Stull, A. T., \& Mayer, R. E. (2007). Learning by doing versus learning by viewing: Three experimental comparisons of learner-generated versus author-provided graphic organizers. Journal of Educational Psychology, 99, 808-820. doi:10.1037/0022-0663.99.4.808

Suzuki, A., Sato, T., \& Awazu, S. (2008). Graphic display of linguistic information in English as a Foreign Language reading. TESOL Quarterly, 42, 591-616.

Sweller, J., van Merrienboer, J. J. G., \& Paas, F. G. W. C. (1998). Cognitive architecture and instructional design. Educational Psychology Review, 10, 251-296. doi:10.1023/A:1022193728205

Tang, G. (1992). The effect of graphic representation of knowledge structures on ESL reading comprehension. Studies in Second Language Acquisition, 14, 177-195. doi:10.1017/S0272263100010810

Vallecorsa, A. L., \& de Bettencourt, L. U. (1997). Using a mapping procedure to teach reading and writing to middle grade students with learning disabilities. Education \& Treatment of Children, 20, 173-189.

Vaughn, S., \& Edmonds, M. (2006). Reading comprehension for older readers. Intervention in School and Clinic, 41, 131-137. doi: $10.1177 / 10534512060410030101$

Vekiri, I. (2002). What is the value of graphical displays in learning? Educational Psychology Review, 14, 261-312. doi:10.1023/A:1016064429161

Venn, J. (1880). On the diagrammatic and mechanical representation of propositions and reasonings. Dublin Pholosophical Magazine and Journal of Science, 9, 1-18. 